\title{
A Retrospective Study of Idiopathic Granulomatous Mastitis at a Tertiary Care Center
}

\author{
Swathi Samalla ${ }^{1}$, M. Lavanya ${ }^{2}$, Triveni Bhopal ${ }^{3}$ \\ ${ }^{1}$ Department of Pathology, Osmania Medical College, Koti, Hyderabad, Telangana, India. ${ }^{2}$ Department of Pathology, \\ Osmania Medical College, Koti, Hyderabad, Telangana, India. ${ }^{3}$ Department of Pathology, Osmania Medical College, \\ Koti, Hyderabad, Telangana, India.
}

\section{ABSTRACT}

\section{BACKGROUND}

Idiopathic granulomatous mastitis (IGM) is a rare benign chronic inflammatory disease of the breast, which is often difficult to differentiate both clinically and radiologically from infectious aetiologies such as tuberculosis, fungal infections, and also from malignancy, thus posing a diagnostic dilemma. Histopathology is essential to solve the dilemma and make a definitive diagnosis. The aim of this study is analysis of idiopathic granulomatous mastitis and its mimics.

\section{METHODS}

This study was done at Osmania Medical College, over a period of 3 years from 2016 to 2019. 30 cases were analysed. Clinicopathological data like pertinent history, clinical and radiological features, and cytological results, was collected from the medical records. All slides were stained with haematoxylin and eosin.

\section{RESULTS}

A total of 30 cases was studied. The study group included women who were 25 to 45 years old; left breast was most commonly involved. The most common presenting symptom was lump $98 \%(\mathrm{n}=29)$ in breast. Mammography revealed skin thickening, parenchymal heterogeneity, irregular mass and focal asymmetric density. Ultrasonography shows ill-defined hypoechoic lesions. On histology, 27 cases (90\%) were diagnosed as idiopathic granulomatous mastitis and 3 cases $(10 \%)$ were diagnosed as tuberculosis granulomatous mastitis.

\section{CONCLUSIONS}

Idiopathic granulomatous mastitis is a benign entity which has varied and nonspecific appearances on ultrasound and mammography and often mimics malignancy and various benign inflammatory conditions of breast. Histopathological examination is necessary to establish diagnosis before deciding upon treatment and also to prevent unnecessary mastectomy.

\section{KEY WORDS}

Chronic Mastitis, Idiopathic Granulomatous Mastitis, Carcinoma Breast
Corresponding Author:

Dr. M. Lavanya,

Upgraded Department of Pathology,

Osmania Medical College,

Koti, Hyderabad-500039,

Telangana, India.

E-mail:drlavanyam@gmail.com

DOI: $10.14260 / \mathrm{jemds} / 2019 / 696$

Financial or Other Competing Interests: None.

How to Cite This Article:

Samalla S, Lavanya M, Bhopal T. A retrospective study of idiopathic granulomatous mastitis at a tertiary care center. J. Evolution Med. Dent. Sci. 2019;8(43):3212-3215, $10.14260 /$ jemds/2019/696

Submission 26-07-2019,

Peer Review 10-10-2019,

Acceptance 16-10-2019,

Published 28-10-2019. 


\section{BACKGROUND}

Idiopathic granulomatous mastitis is a rare benign chronic inflammatory disease of breast that involves mainly women of childbearing age.1,2,3,4 The disease, was first described by Kessler and Wollock in $1972 . .^{5}$ The etiopathogenesis of IGM is unknown but some factors causing reaction to chemical materials such as OCP, infectious disease, autoimmune diseases and immunologic response for milk leakage from the breast's lobule. ${ }^{3,6}$ Also conditions like pregnancy, breast feeding, hyperprolactinemia, galactorrhoea, and alpha 1 antitrypsin deficiency have been associated with the risk of the disease. Most common clinical features are breast mass, pain, skin changes, axillary lymphadenopathy, inflammation may not always be present clinically, thus leading to misdiagnosis as a malignant lesion. Ultrasound findings are an irregular hypo echoic lesion that connects with the tubular hypo echoic area, parenchymal heterogeneity and an area of mixed echo pattern with parenchymal deformity, both of which can lead to diagnosis of malignant changes. Mammography imaging are asymmetric diffuse, skin thickness. Both ultrasound and mammography are unable to differentiate IGM from malignant or other benign lesions, especially inflammatory breast cancers. ${ }^{4,5,6}$ So it is often difficult to differentiate idiopathic granulomatous mastitis both clinically and radiologically from malignancy of the breast especially inflammatory breast cancers, thus, posing a diagnostic challenge. Histopathology is essential for make a definitive diagnosis.

\section{METHODS}

It was a retrospective study. This study was done at Osmania general hospital/medical college over a period of 3 years from 2016 to 2019.30 cases were analysed. Sample size was taken based on the convenience of the study. Clinicopathological data was collected from the medical records like pertinent history, clinical and radiological features, and cytological results. The specimens were fixed in $10 \%$ neutral buffered formalin. They were examined grossly according to the standard guidelines, with special emphasis on the tumour size and lymph node status of the lesion. The specimens were grossed, and sections were taken from representative sites. These sections were then processed in tissue processor and embedded in paraffin wax. Four to fivemicron thickness sections were prepared from the corresponding paraffin blocks, one on albumin coated slide for Haematoxylin and Eosin (H \& E) staining.

SPSS Ver. 20 was be used for Data Analysis. Mean, median, and SD are used to describe quantitative data. Qualitative data are summarized using frequency and percentage.

\section{RESULTS}

The study was conducted over a period of 3 years from 2016 to 2019 at a tertiary care center Osmania medical college,
Hyderabad, Telangana state, India. A Total number of 30 cases were studied. The study group included women of age 25 to 45 years old. Left breast was most commonly involved 18 cases $(60 \%)$ and right breast $12(40 \%)$ cases noted. History of lactation and Pregnancy were also enquired, no association noted.

\section{Clinical Features}

The patients presented with various complaints like lump, discharge, pain, skin changes and axillary lymphadenopathy. Almost all the patients 29 out of 30 (98\%) presented with lump. Skin changes like peau de orange, ulcer, ulcer with discharge were noted in 12 (40\%) out of 30 patients. 11 ( 6 ) patients presented with discharge along with lump and skin changes. $20(60 \%)$ patients noted pain, 8 (26\%) patients showed axillary lymphadenopathy. Lump with skin changes and axillary lymphadenopathy posed a great clinical diagnostic dilemma

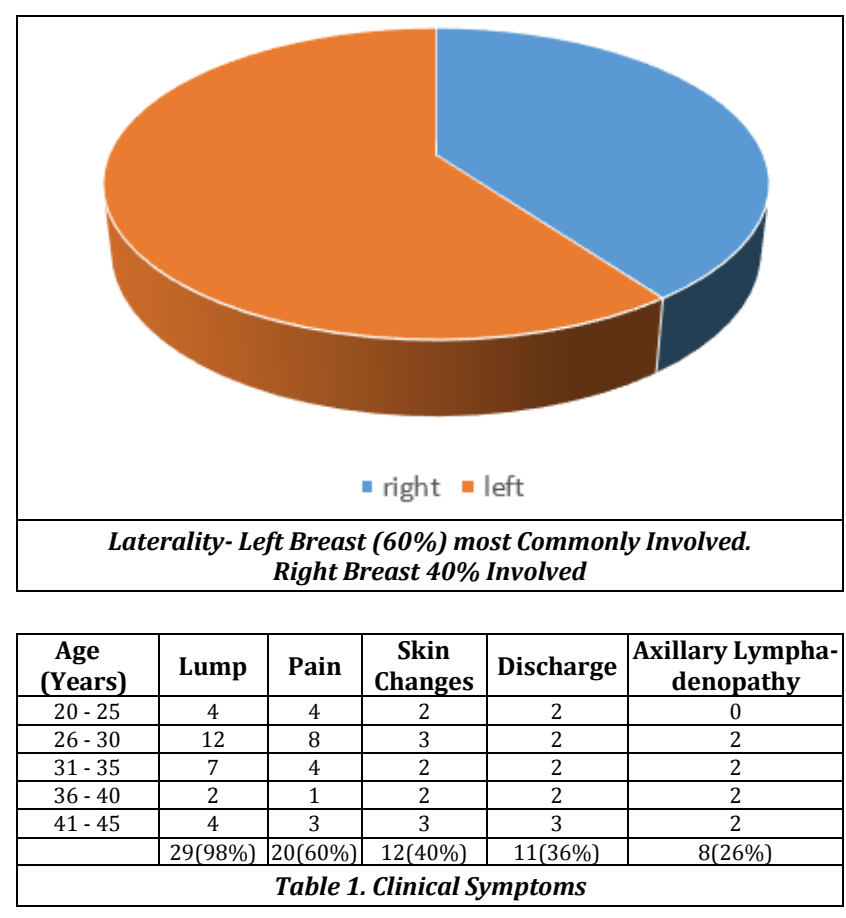

Most common clinical symptom was lump in the breast $98 \%$ (29 of cases out of 30 ), followed by pain, skin changes, discharge, axillary lymphadenopathy.

\section{Imaging Modality}

In our study 12 patients underwent ultrasonography and Mammography. In Ultrasonography ( Fig. 1-a) 5 cases showed ill-defined hypoechoic lesions with parenchymal deformity and 7 cases showed parenchymal heterogeneity and an area of mixed echo pattern. Mammography (Fig. 1 -b) 8 cases showed parenchymal heterogeneity, irregular mass skin thickening, in 4 cases focal asymmetric density noted.

\section{Cytology}

In all cases with lump, lump with skin changes and lump, skin changes \& axillary lymphadenopathy with inconclusive radiologic findings cytology aided in arriving at a diagnosis of Idiopathic granulomatous mastitis. Cytosmear of breast lump (Fig. 2-10x, 40x- H\&E) shows sheets of ductal epithelial cells, inflammatory cells, giant cells, plasma cells occasional 
epithelioids on a hemorrhagic background suggestive of Idiopathic granulomatous mastitis.

\section{Histopathology}

Grossly (Fig. ) cut section shows grey white in colour and fleshy and focal necrosis seen in some cases. Tumor size ranged between a minimum of $2 \mathrm{~cm}$ to maximum of $12 \mathrm{~cm}$. On histology, 27 cases (90) diagnosed as Idiopathic granulomatous mastitis, 3 cases $(10 \%)$ Tuberculosis granulomatous mastitis. Histopathology (Fig. 3- 10x, 40xH\&E sections) studied from the breast lumps showed breast parenchyma with ducts and acini, focal areas shows illdefined granulomata with collections of epithelioid histiocytes, lymphoplasmacytic cells, Langhans and foreign body type of giant cells, plenty of neutrophils and congested blood vessels along with duct ectasia and periductal inflammation suggestive of Idiopathic granulomatous mastitis.In Tuberculosis granulomatous mastitis breast tissue with extensive areas of multiple caseating granulomas composed of central caseation rimmed by epithelioid and Langhan's type of giant cells, chronic inflammatory cells seen.

\section{DISCUSSION}

Idiopathic granulomatous mastitis is a rare benign and chronic inflammatory breast disease that mainly involves women in childbearing age group. The disease was first described by Kessler and Wollock in 1972. In our study most of the cases were in reproductive age group with mean age of 32.6 years. It is a benign condition, but it is difficult to diagnose \& treat the patient due to clinically and mammographically mimics breast cancer especially inflammatory type ${ }^{4}$. IGM is characterized by sterile noncaseating lobulocentric granulomatous inflammation. .,8 It $^{-1}$ is usually associated with lactation and hyperprolactinemia..$^{9-12}$ The exact cause remains unknown and the diagnosis is usually made by means of exclusion. In our study there was no correlation to lactation. The clinical and radiologic findings of IGM are known to frequently overlap with those of breast cancer and several benign inflammatory breast conditions and thus can often lead to misdiagnosis and delayed treatment. In our study all cases with lump, lump with skin changes and lump, skin changes \& axillary lymphadenopathy with inconclusive radiologic findings cytology aided in arriving at a diagnosis of Idiopathic granulomatous mastitis. The most accepted theory is that an initial insult to the ductal epithelial cells in the breast causes a transition of luminal secretions to the lobular breast stroma. This transition causes a local inflammatory response in the connective tissue, with macrophage and lymphocyte migration to the region, and subsequently a local granulomatous response. ${ }^{10}$ Multiple inflammatory breast diseases that result from various conditions including periductal mastitis and mammary duct ectasia, have been proposed to coexist in a pathologic spectrum. These diseases have been conceptually grouped into a body of entities called as the mammary duct-associated inflammatory disease sequence (MDAIDS).13

Pregnancy, lactation, hyperprolactinemia, $\alpha 1$-antitrypsin deficiency, oral contraceptive use, trauma, diabetes, autoimmune disease, and smoking are most common precipitating factors. But pregnancy, lactation, and hyperprolactinemia are the only factors with well-established associations with IGM.14,15 Most common clinical presentations tender breast lump that may be of firm to hard consistency, skin changes erythema, purulent discharge, lymphadenopathy \& nipple retraction. Bilateral involvement is rare.

Focal asymmetric density is the most common mammographic pattern seen in idiopathic granulomatous mastitis according to Yilmaz et al. ${ }^{16}$ Diffuse unilateral increase in breast density, more often seen in malignancies may also be encountered in IGM. Ultrasound imaging shows hypoechoic or heterogeneous mass with characteristic tubular hypoechoic extensions connecting the dominant mass to smaller nearby masses ${ }^{17}$. Parenchymal heterogeneity and distortion with or without acoustic shadowing may also be seen with absence of a definite mass. Both mammographic and ultrasound findings of idiopathic granulomatous mastitis are nonspecific and may often mimic carcinoma, a definitive histopathological diagnosis is essential before giving treatment and surgical procedure.

Cytology of IGM shows numerous lymphocytes and plasma cells with granulomas formed of epithelioid histiocytes and multinucleated giant cells. The cytological diagnosis of IGM is difficult because the features overlap with other aetiologies, including tuberculosis.

\section{Histopathologic Analysis of IGM}

A distinctive histopathologic feature of IGM is noncaseating lobulocentric granulomatous inflammation. This inflammation is usually confined to at least centred in the breast lobules generally sparing major ducts and surrounding fat tissue. It is also called as granulomatous lobular mastitis so that it can be distinguished from granulomatous periductal mastitis. ${ }^{8}$ Within the inflamed lobules there may be lymphocytes, plasma cells, eosinophils, and neutrophilic micro abscesses. Sterile granulomas also are seen invariably and are composed of epithelioid histiocytes and Langhans giant cells, which may also have a suppurative centre. Most common differential diagnosis of IGM is inflammatory breast carcinoma, despite the name, is actually not an inflammatory process it is characterized by an extensive angiolymphatic spread of carcinoma that produces a pseudo inflammatory clinical and imaging appearance, ${ }^{18}$ which is characterized by infiltrating irregular and angulated nests of epithelial cells with cytological atypia within a desmoplastic background.

IGM may have features that are clinically suspicious for malignancy, but based on histological features other inflammatory conditions are most common differential diagnosis infection in particular. When granulomatous inflammation is present, microbial stains are usually are performed. To confirm mycobacteria and fungal infections acid-fast and Fite stains, for fungi periodic acid-Schiff and Gomori methenamine silver stains are performed. ${ }^{19}$ Noninfectious inflammatory processes included in the histopathologic differential diagnoses of IGM are ductal ectasia, plasma cell mastitis, foreign body granulomas, and sarcoidosis. The histologic finding of ductal ectasia is cystic duct dilatation with surrounding lymphoid and histiocytic inflammation that is distinctly ductocentric, rather than lobulocentric, and nongranulomatous. ${ }^{20,21}$ In plasma cell mastitis, histology shows granuloma with periductal, 
perilobular, and stromal components of the breast tissue infiltrated by inflammatory cells heavily plasmacytic.22 Foreign body granulomas may be seen in association with a variety of processes, including fat necrosis and injected foreign breast augmenting material, in these situations usually inflammatory cells seen in stroma of breast tissue. Sarcoidosis may be difficult to distinguish from IGM with histologic analysis alone, granulomas are usually located in the interlobular stroma. And isolated mammary sarcoidosis is infrequently reported, extramammary findings of sarcoidosis are present. ${ }^{23}$

The treatment of IGM remains controversial. Treatment options include conservative therapy with corticosteroids ${ }^{24}$ and the more aggressive approach of wide local surgical excision. 25

\section{CONCLUSIONS}

Idiopathic granulomatous mastitis is a benign entity which has varied and nonspecific appearances on ultrasound and mammography and often mimics malignancy; hence, histopathological evaluation is necessary to establish diagnosis before deciding upon treatment, and also to prevent unnecessary mastectomy.

\section{REFERENCES}

[1] Bellavia M, Damiano G, Palumbo VD, et al. Granulomatous mastitis during chronic antidepressant therapy: is it possible a conservative therapeutic approach? J Breast Cancer 2012;15(3):371-2.

[2] Garcia-Rodiguez JA, Pattullo A. Idiopathic granulomatous mastitis: a mimicking disease in a pregnant woman: a case report. BMC Res Notes 2013;6:95.

[3] Kalaycı TÖ, Koruyucu MB, Apaydın M, et al. Idiopathic granulomatous mastitis associated with erythema nodosum. Balkan Med J 2016;33(2):228-31.

[4] Gurleyik G, Aktekin A, Aker F, et al. Medical and surgical treatment of idiopathic granulomatous lobular mastitis: a benign inflammatory disease mimicking invasive carcinoma. J Breast Cancer 2012;15(1):119-23.

[5] Ergin AB, Cristofanilli M, Daw $\mathrm{H}$, et al. Recurrent granulomatous mastitis mimicking inflammatory breast cancer. BMJ Case Rep 2011;2011. pii: bcr0720103156.

[6] Patel RA, Strickland P, Sankara IR, et al. Idiopathic granulomatous mastitis: case reports and review of literature. J Gen Intern Med 2010;25(3):270-3.

[7] Kessler E, Wolloch Y. Granulomatous mastitis: a lesion clinically simulating carcinoma. Am J Clin Pathol 1972;58(6):642-6.

[8] Going JJ, Anderson TJ, Wilkinson S, et al. Granulomatous lobular mastitis. J Clin Pathol 1987;40(5):535-40.
[9] Al-Khaffaf B, Knox F, Bundred NJ. Idiopathic granulomatous mastitis: a 25-year experience. J Am Coll Surg 2008;206(2):269-73.

[10] Altintoprak F, Karakece E, Kivilcim T, et al. Idiopathic granulomatous mastitis: an autoimmune disease? Sci World J 2013;2013:148727.

[11] Bani-Hani KE, Yaghan RJ, Matalka II, et al. Idiopathic granulomatous mastitis: time to avoid unnecessary mastectomies. Breast J 2004;10(4):318-22.

[12] Nikolaev A, Blake CN, Carlson DL. Association between hyperprolactinemia and granulomatous mastitis. Breast J 2016;22(2):224-31.

[13] Bland KI, Copeland EM. The breast: comprehensive management of benign and malignant diseases. Philadelphia, Pa: Saunders/Elsevier 2009.

[14] Kim J, Tymms KE, Buckingham JM. Methotrexate in the management of granulomatous mastitis. ANZ J Surg 2003;73(4):247-9.

[15] Taylor GB, Paviour SD, Musaad S, et al. A clinicopathological review of 34 cases of inflammatory breast disease showing an association between corynebacteria infection and granulomatous mastitis. Pathology 2003;35(2):109-19.

[16] Yilmaz E, Lebe B, Usal C, et al. Mammographic and sonographic findings in the diagnosis of idiopathic granulomatous mastitis. Eur Radiol 2001;11(11):223640.

[17] An YY, Kim SH, Cha ES, et al. Diffuse infiltrative lesion of the breast: clinical and radiologic features. Korean J Radiol 2011;12(1):113-21.

[18] Amparo RS, Angel CD, Ana LH, et al. Inflammatory breast carcinoma: pathological or clinical entity? Breast Cancer Res Treat 2000;64(3):269-73.

[19] Pereira FA, Mudgil AV, Macias ES, et al. Idiopathic granulomatous lobular mastitis. Int J Dermatol 2012;51(2):142-51.

[20] Dixon JM, Anderson TJ, Lumsden AB, et al. Mammary duct ectasia. Br J Surg 1983;70(10):601-3.

[21] Webb AJ. Mammary duct ectasia: periductal mastitis complex. Br J Surg 1995;82(10):1300-2.

[22] Adair FE. Plasma cell mastitis: a lesion simulating mammary carcinoma: a clinical and pathologic study with a report of 10 cases. Arch Surg 1933;26(5):735-49.

[23] Banik S, Bishop PW, Ormerod LP, et al. Sarcoidosis of the breast. J Clin Pathol 1986;39(4):446-8.

[24] Erozgen F, Ersoy YE, Akaydin M, et al. Corticosteroid treatment and timing of surgery in idiopathic granulomatous mastitis confusing with breast carcinoma. Breast Cancer Res Treat 2010;123(2):44752.

[25] Ahmed YS, Abd El Maksoud W. Evaluation of therapeutic mammoplasty techniques in the surgical management of female patients with idiopathic granulomatous mastitis with mild to moderate inflammatory symptoms in terms of recurrence and patients' satisfaction. Breast Dis 2016;36(1):37-45. 